\title{
The Revival of the Bamboo Sector in India and Its Relevance to Sustainable Development
}

\author{
Sharayu Bhakare ${ }^{1^{*}}$ \\ ${ }^{1}$ Symbiosis College of Arts and Commerce, Pune City, India \\ *Corresponding Author. Email: sharayu.bhakare@symbiosiscollege.edu.in
}

\begin{abstract}
Bamboo can serve as a mean to achieve the UN framed Sustainable Development Goals (SDG) and spur sustainable development. It belongs to the grass family Poaceae (Gramineae) and becomes a significant part of forest ecology. The main objective of this research is to explore the bamboo sector in India by analyzing the three dimensions of this sector: Ecology, Ecosystem, and Economy (3Es). The Covid-19 Pandemic has stagnated the progress of this sector, which can be revived with strategies suggested in this research paper. This exploratory and qualitative research uses a conceptual approach to develop models based on data collection and analysis. Through secondary data, literature review, and in-depth interviews of experts, this study explored the 3Es and integrated them into the 3Ps of the Triple Bottom Line: Profit, Planet, and People, which is a concept proposed by John Elkington to measure sustainable development. This research paper proposed a bamboo Triple Bottom Line. Based on the collected data, a universal four-stage operational model was identified for methodically harnessing the potential of this resource.
\end{abstract}

Keywords: Sustainable development, green gold, livelihoods, ecology, ecosystem, economy, bamboo Triple Bottom Line

\section{INTRODUCTION}

As the world undergoes catastrophic climate change, there is a need to adopt more sustainable ways of leading lives by striving for a green economy. As per the UN Environment Program, 'Green Economy' is the one that ensures the wellbeing of humans, brings about social equity, lowers environmental risks, and eliminates ecological scarcity [27]. In its simplest expression, an economy that lowers carbon emissions, uses resources sustainably and judiciously, and is composite of all the sections of society, is called a 'Green Economy' [3]. Harnessing the potential of this renewable plant species of bamboo for social and economic sustainable development is imperative to transit to a green economy. The UN framed SDGs are the blueprint for achieving a sustainable future for the world. It is expected that by the year 2030, these interconnected SDGs are achieved. The International Bamboo and Rattan (INBAR) organization recognizes bamboo as a strategic resource and has identified its contribution to six SDGs namely, End poverty (SDG1), Provide affordable and sustainable energy resources (SDG7), Access to adequate and affordable housing (SDG11), efficient use of natural resources (SDG 12), Address climate Change (SDG 13), Protect and restore terrestrial ecosystems (SDG 15). An interesting insight, therefore, is that bamboo plantations can serve as a mean to spur sustainable development. Due to its innumerable uses and medicinal properties, bamboo is referred to as Green Gold in India. But the Covid-19 Pandemic has hampered the progress of this sector, which can be revived with strategies suggested in this research paper. However, there is a need is to raise a few legitimate questions such as: Is this resource is given due recognition? Is the potential of the 'Green Gold' optimally unleashed? What is the present status and contribution of the bamboo sector? This study is an endeavor to provide solutions to these critical questions through a three-dimensional analysis and 'Four-Stage Operational Model'. This study focused on India, as lessons for other emerging economies.

\subsection{Related Work}

The extant literature highlights the implications of SDGs, and contribution and challenges of the bamboo sector in different countries. [22] has mapped the relation of 17 SDGs to common sustainability targets like poverty eradication, hunger elimination, reduced inequality, and has inferred a direct relationship with these variables highlighting the role of SDGs in minimizing social challenges. However, according to the data of INBAR report 2009, bamboo should first be deployed as a tool for sustainability in the countries where it is cultivated, and not be transported over thousands of kilometers to western markets where locallygrown renewable resources may perform better in terms of eco-costs. A study conducted by [14] asserts that in a developing economy, the bamboo sector can be a key livelihood provided as 60 million workdays are generated by commercial harvesting. [19] examined bamboo processing as an income-generating or business activity, and also regretted that it is largely undeveloped and is 
primarily based around handicraft and household processing. The authors suggested that countries should develop administrative strategies to guide an enabling business climate benefiting from the local and global bamboo market demand. A recommendation document of INBAR at the UN Summit for the Adoption of the Post2015 Development Agenda discussed the means of harnessing the bamboo resources for sustainable development. Bamboo-based industries suffer from the lack of infrastructure and market linkage framework, and therefore need handholding support for infrastructure and marketing [6].

[2] proposed about increasing the degree of commercializing bamboo cultivation through large-scale contract in farming and cooperative and commercial forestry, establishing small enterprises for processing the bamboo and educating small-enterprise owners and workers on best practices for efficiency, and establishing linkages between these enterprises and manufacturers.

\subsection{Research Contribution}

This research paper concluded that the bamboo industry needs to be developed to the level of the timber industry to be able to better compete in price. From the literature reviewed, it is reflected that the efforts to optimally promote the green gold for sustainable development are fragmented. Hence, the researcher has to put forth a comprehensive framework from three perspectives (economy, ecology, and ecosystem) and suggests a 'Bamboo Triple Bottom Line' and the 'Four-Stage Operational Model' by answering the following research question - How can the developing economies with green gold resource of bamboo explore its economy, ecology and ecosystem dimensions for sustainable development through profit, planet, and people approach?

\subsection{Paper Structure and Research Methodology}

The main objective of this research was to examine the bamboo sector in India by analyzing the three dimensions of this sector: Ecology, Ecosystem, and Economy (3Es). This exploratory and qualitative research uses a conceptual approach to develop models based on data collection and analysis. Through the evaluation of secondary data, review of literature, in-depth interviews of experts and practitioners, the transcript was constructed to infer the significance of the bamboo sector to a developing economy. An attempt was made to develop a 'Bamboo Triple Bottom Line (TBL)' based on the TBL concept proposed by John Elkington for sustainable development. This study endeavors to develop a universal 'Four-Stage Operational Model' for this sector, to draw the attention of the policymakers and stakeholders to the enormous potential bamboo holds. The scope of the study was limited to a birds'-eye view of the bamboo sector in India perceiving scope for in-depth research on each dimension in 3Es and every stage in the 'Four-Stage Operational Model'.

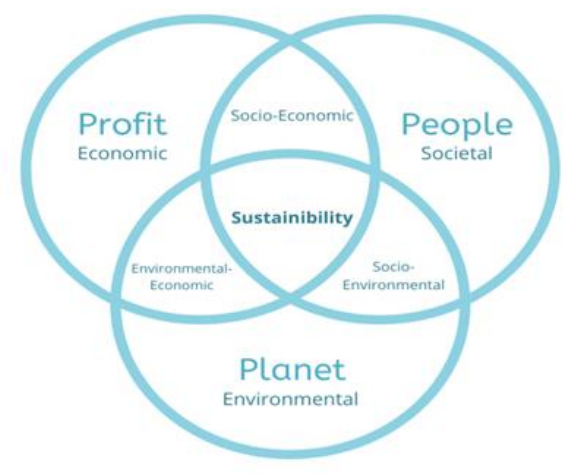

Triple Bottom Line

Figure 1 The Concept of Triple Bottom Line

\section{BACKGROUND}

In the year 1994, John Elkington conceived the term "Triple Bottom Line (TBL)", a route to sustainable development. The TBL incorporates the significance of environmental, economic, and social performance for sustainable development. This is encapsulated in 3Ps, which are Planet, People, and Profit. As per the TBL, 'Profit' or economic performance is not the sole measure to attain sustainability. For benchmarking sustainable development, Profit has to be accompanied by 'Planet' or environmental performance, and 'People' or social performance [8].

This concept has been accepted by many countries and organizations across the world to measure their performance on sustainable development. This research paper established the relevance of TBL in the bamboo sector.

\section{DISCUSSIONS}

The researcher observed that there are multiple impediments in the growth of this sector, which are weak implementation mechanisms, under-utilized value-chains, lack of funding to entrepreneurs, absence of robust marketing-channels, inadequate government support, and fragmented efforts.

India, as a developing economy, having sixty percent of the rural population, will be able to expedite the development process, if the bamboo resources are effectively channelized.

\subsection{The Bamboo Triple Bottom Line}

This framework was developed by the researcher based on the three-dimensional analysis of bamboo, which are Ecology, Economy, and Eco-System. 


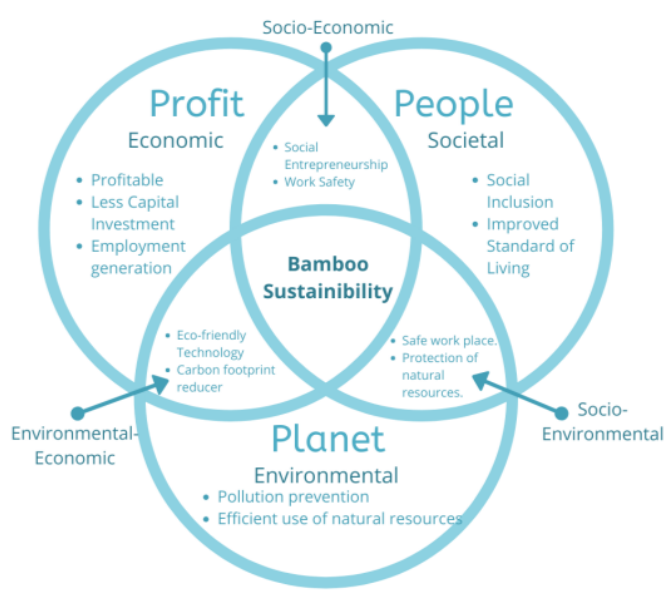

Figure 2 Bamboo Triple Bottom Line (Conceptualized and Proposed by the Researcher)

\subsubsection{Planet}

Indian government, state-government, non-government organizations, financial institutions, and private individuals are taking considerable efforts in conserving and growing bamboo which is evident from the innumerable institutions established for promoting bamboo.

\subsubsection{People}

The bamboo sector can contribute effectively in social development. It has the potential to provide livelihood opportunities to the rural poor by creating employment in the bamboo craft and marketing segment.

\subsubsection{Profit}

The bamboo sector can potentially contribute to a country's economy through its commercial businesses, trade, and employment generation.

Based on a thorough understanding of the bamboo triple bottom line, the researcher conceived and proposed a 'Four-Stage Operational Model' that could be universally implemented to harness the potential of this sector.

\subsection{The Four-Stage Operational Model}

From the data collected through in-depth interviews of experts and secondary sources, four stages were identified in the bamboo value-chain. These are then logically arranged to construct a universally-applicable operationalmodel which provides a systemic framework of the bamboo sector with engagement possibilities for all of the stakeholders.

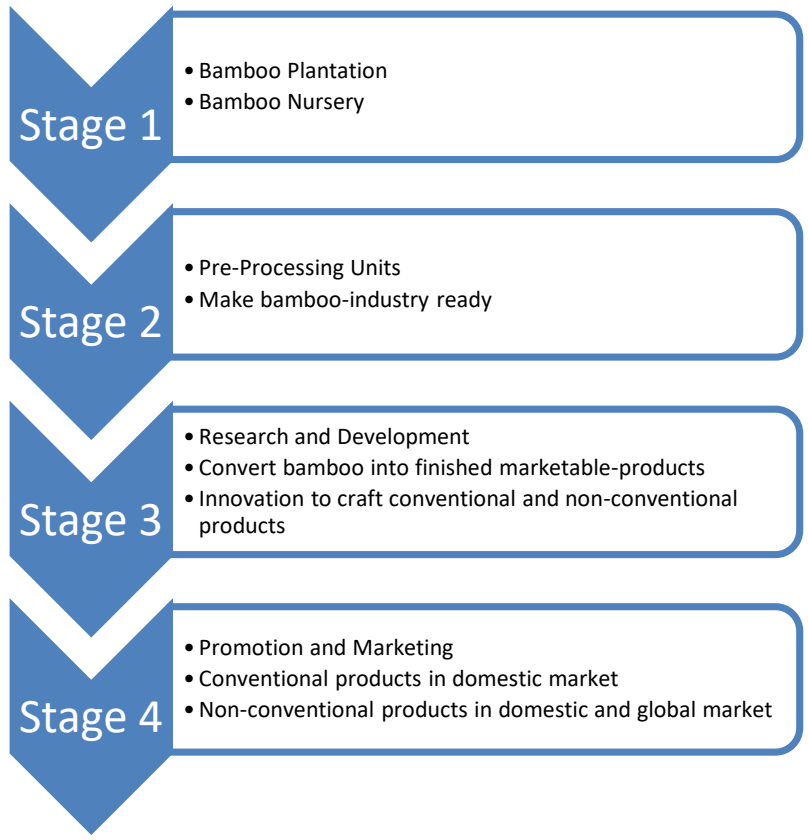

Figure 3 The 'Four-Stage Operational Model' of the Bamboo Sector

(Conceptualized and Proposed by the Researcher)

Stage 1: In this stage, the emphasis is on maintaining and developing the bamboo ecology through plantations and nurseries. This is done by farmers either individually or with the help of farmer-producing organizations (FPOs). There is abundant opportunity for farmers to be agripreneurs (agriculture entrepreneurs) and for individuals to start their bamboo nurseries. Interventions from State bamboo boards as the funding entity and Forest department as the implementing agency is imperative to nurture this stage. FPO is an effective way to undertake cooperative farming. Cultivating on marginal-land holdings is not economically feasible, therefore, more FPOs should be formed or farmers should be encouraged into cooperative farming. Bamboo samplings are distributed free, but there is less awareness about the plantation. The Forest department needs to conduct training programs for farmers. Agriculture Universities can institute a course in bamboo farming to encourage youth. Barren land with the State-Farming Corporations could be occupied for bamboo cultivation. A public-private partnership model could be an effective way to do this.

Strengthened linkages of entrepreneurs with farmers could encourage more farmers to understand the specific bamboo requirement and cultivate accordingly. A collaborative and cooperative approach to cultivating bamboo will result in reducing the risks and maximizing the harvest.

Stage 2: The second stage is processing the harvested bamboo by felling and cleaning. Here the bamboo is converted into industry-ready raw material and transported to the workshops for crafting finished-products. These processing units are termed as Common Facility Centers (CFCs). These are owned by the state Bamboo 
Development Board, but could be operated by FPOs, individuals, farmers, or as backward integration by entrepreneurs who manufacture products. These processing centers need to be strengthened with technology, trainers, and managerial personnel. This can be an excellent entrepreneurial avenue.

Stage 3: The third stage is the research, product design, and development stage. Innovation is the essence here. Artisans and entrepreneurs are creatively-engaged in making conventional and non-conventional products from bamboo. Organizations such as CIBART bring in technologies, experts, tools, and machines for the rural communities so that they can create a model that is financially viable through the production of handicrafts, furniture, and other structures made of bamboo. There is a need for 'Made in India' initiatives to priorities bamboo entrepreneurship through funding and skilling.

Stage 4: This is the most-crucial stage wherein the final products made from bamboo are sold to the consumers. In India, the basic means of showcasing the products is through exhibitions. However, e-commerce is emerging as a new platform to sell these products. The government can be the biggest consumer of bamboo products.

If the bamboo sector / industry has to be scaled sustainably, it is necessary to realize that each stage has an independent Triple Bottom Line that needs to be nurtured. Government departments such as Mahabamboo could articulate a Triple Bottom Line for each stage and endeavor to reach the benchmarks of three Ps (Profit, People, and Planet) in collaboration with the Forest department. In this process, they could encourage the engagement of more farmers, artisans, entrepreneurs, and other relevant stakeholders.

\section{IMPLICATIONS}

\subsection{Managerial Implications}

The Four-Stage Operational Model is applicable in countries that aim at a thriving bamboo ecology, robust bamboo eco-system, and buoyant economy. A wellexecuted plan of action should be drafted by the State Bamboo development agencies such as Mahabamboo, ensuring efficient implementation. This model will help policy-makers to look at each stage as an independent segment and identify stakeholders, map funding requirements, resource needs, professional insights, institutional engagement, and managerial know-how for marketing the finished-products. It will help to identify artisan clusters and provide impetus to rural entrepreneurship. Wherever necessary, establishing forward and backward linkages can help create rural employment with special reference to women artisans. The development agencies at the state-level could identify this framework region wise, e.g. district.

With an organized and professional approach, this sector can be a huge contributor to a balanced regional development.

\subsection{Practical Implications}

There is a need for concerted and convergent efforts in developing the bamboo ecology, ecosystem, and economy. An in-depth understanding of the proposed frameworks can provide a direction to the policy-makers in developing the bamboo sector. With better understanding and adoption of this model regions with bamboo, can realize the longneeded regional development. Furthermore, the growth and development of this sector promising better income and livelihood, can be seen as a sector that can witness pulleffect or reverse-migration of sons of the soils, thereby reducing the burden on urban cities.

Though dedicated initiatives taken by some individuals, state, and private organizations, the outcome is not noteworthy. Some suggestions for the development and visibility of bamboo-based industries are as follows:

1. Instituting special courses on the bamboo plantation by agriculture universities as well as grass-root organizations to encourage more farmers to shift to bamboo farming.

2. Corporates could be directed to channelize their CSR funding to support and promote bamboo farmers and artisans.

3. State-farming corporations can use their barren land for bamboo cultivation.

4. Financial institutions and banks should be directed to consider the bamboo handicraft start-ups under priority funding / lending.

5. At the macro-level, the government could invite more Foreign Direct Investment (FDI) in setting-up industries that have the highest consumption of bamboo, i.e. paper, biogas, and coal.

6. Bamboo handicraft start-ups should be exposed to domestic and global marketing platforms.

7. Bamboo artisan clusters can be developed into handicraft centers to promote destination tourism [1].

8. Local-specific business models between smallholders and the private sector could be conceived to encourage cultivation, harvesting, processing, and product development (INBAR project in Asia, 2018).

9. More youth should choose to promote and develop this sector in any way that may interest them.

Amid the Covid-19 Pandemic, the world needs an economic and social resurgence. India's mission of self-reliance but in a sustainable way, can be achieved by a greener economy. Channelizing the potential in bamboo grass by addressing the issues in Triple Bottom Line, i.e. profit, planet, and people can foster the development and pave way for inclusive growth and a more sustainable future for India.

\section{CONCLUSION}

The bamboo sector in India has tremendous potential if explored in an organized and strategic way. The bamboo triple-line conceptualized by the researcher brings to the forefront the sustainability of this sector through the people, planet and profit dimensions. Bamboo has the 
potential to generate income and livelihood thereby enabling social development. The increase in bamboo plantations by various organizations has the prospect of contributing to the environment. Furthermore, implementing the 'four-stage operational model' proposed by the researcher will harness and capitalize this resource to economically leverage India, a developing country.

\section{REFERENCES}

[1] Arya V, Sharma S, Sethi D, Verma H, Shiva A, Ties that bind tourists: embedding destination motivators to destination attachment: A study in the context of Kumbh Fair, India, 2018.

[2] Baksy Aniket, 'The bamboo industry in India, supply chain structure, challenges and recommendations', CCS working paper 2013.

[3] Bamboomitra, bi-annual newsletter, June 2013.

[4] Bamboo Conservation, Management and Utilization in India, A Status Report, Indian Council of Forestry Education and Research (ICFER), 2017.

[5] Bamboo Market Size and Share, Global Industry Report (2019-2025).

[6] Borah, Nandini, A case study of bamboo-based industry in Mizoram. (www.papers.ssrn.com, 2019)

[7] Gauli Kalyan, Durai Jayraman, Oduor Nellie, 'Value chain analysis and market assessment of Bamboo products in Kenya', INBAR working paper, 2018.

[8] Elkington John, Cannibals with forks: The triple bottom line of $21^{\text {st }}$-century business, Capstone, 1997.

[9] Gupta Anu, Kumar Ajit, Potential of bamboo in sustainable development, Asia-Pacific Journal of Management, Research and Innovation, 2008.

[10] Jacob Kibwage, Alponce J, Odondo and Grace M, Structure and performance of formal retail market for bamboo products in Kenya, Scientific Research and Essays, 2008.

[11] Alavika Vyavhare, Bamboo Poor Man's Gold, A case for developing the bamboo sector in India, CSS working paper, 2009.

[12] Motta R, The Sustainable development goals and $1.5^{*} \mathrm{C}$ climate change.
[13] Na Shen, Kevin Au, Lalln Yi, Diversification strategy, ownership structure, and financial crisis: Performance of Chinese private firms, Asia-Pacific Journal of Financial Studies, 2018.

[14] Pande V. C., Economic analysis of bamboo plantation in three major ravine systems of India, Agriculture Economics Research Review, Issue 1, Vol $25,2012$.

[15] Ramakrishnan M, Role of bamboo in ecosystem', Austin Journal of Environmental Toxicology, Austin Publishing Group, 2018.

[16] Ramaswami Rama, Entrepreneurship Development of Bamboo based Enterprises in Bairabi Cluster, Mizoram, Mizoram University Journal of Humanities and Social Sciences, Vol 5, Issue 2, December 2019.

[17] Report on China Bamboo Industry Plans at National and Provincial Levels, INBAR 2020.

[18] State of Forest Report, 2019, published by Forest Survey of India, Chapter 8, Bamboo resources of the country.

[19] Sythud Phimmachanh, Zhang Ying, Mukete Beckline. Bamboo Resources Utilization: A Potential Source of Income to Support Rural Livelihoods. Applied Ecology and Environmental Sciences. Vol. 3 (6), 2015, pp 176-183. http://pubs.sciepub.com/aees/3/6/3

[20] Vogtlander Joost, Lugt Pabli, Brezet Han, The sustainability of bamboo products for local and Western European applications. LCAs and land-use, Journal of Cleaner Production, 2010.

[21] Vos Robert Jan, Structural Bamboo in the Netherlands, 2014.

[22] Zaini S, Akhtar A, Modelling the sustainable development goals for India: An interpretive structural modeling approach, World Review of Science Technology and Sustainable Development, Vol. 15 (1), 2019.

[23] www.aidcltd.com

[24] www.fsi.nic.in >forest-report-2019

[25] www.inbar.int

[26] www.un.org/sustainabledevelopment/ biodiversity/

[27] www.unenvironment.org 